\title{
An Empirical Study About Illegal Information Disclosure of Listed Companies
}

\author{
Xiaodong Lv \\ China College of Economic Administration of China \\ University of Petroleum (East China) \\ Shandong Qingdao, China \\ Email:lvxiaodong1980@126.com
}

\author{
Hao Ding \\ China College of Economic Administration of China \\ University of Petroleum (East China) \\ Shandong Qingdao, China \\ Email:dinghao@upc.edu.cn
}

\begin{abstract}
Using a paired t-test, Wilcoxon test and logistic regression analysis to analyze the 196 listed companies of illegal information disclosure in Shanghai and Shenzhen A-shares and matching companies in 2007-2012, this paper carries out an empirical research about the factors affecting illegal information disclosure of listed companies, finding that: Ownership concentration, the board stability, profitability, solvency and the level of development of the external market show significant negative correlation with the probability of illegal information disclosure, Managers Equity Incentives shows significant positive correlation with the probability of illegal information disclosure, while the proportion of independent directors, audit committee established or not, the degree of legal protection and audit oversight opinions don't have significant relationship with illegal information disclosure.
\end{abstract}

Keywords: listed company; external environment; illegal information disclosure

\section{INTRODUCTION}

Information disclosure of listed companies, which can enhance the company's own value and maintain market stability and development, is the key factor to protect the interest of investors. High quality information disclosure can reduce the likelihood of occurrence of opportunism and moral hazard, and plays an essential role in promoting the efficiency of capital market.

In recent years, scholars researched on the causes and affecting factors about illegal information disclosure from the governance structure, financial situation and other internal perspective respectively, and got valuable results. Most of these studies focused on the influence of company size, ownership structure, board governance, financial condition and other characteristics of the company's internal on illegal information disclosure, while paid little attention to the external environment, and also focused on the related factors before the implementation of new accounting standards. Based on the research results of the relevant literatures, this paper takes the company's internal characteristics and external environment into account, and focuses on the period after the implementation of the new accounting standards in order to fill the gap of previous researches on illegal information disclosure of listed companies and provide references for business decision-makers and government regulators.

\section{LITERATURE REVIEW AND RESEARCH HYPOTHESIS}

A. The Influence of Governance Structure on Illegal Information Disclosure

(1) Ownership Concentration and Illegal Information Disclosure

According to the study of Wu Guo-ping and Huang
Zheng(2012), under the influence of Entrenchment Effect, higher ownership concentration leads to lower quality of information disclosure, which is not conducive to restrain illegal information disclosure; under the influence of Alignment Effect, vice versa. Therefore, in view of the situation that China's listed companies are relatively high ownership concentration, we propose the following hypothesis:

H1: Ownership concentration shows negative correlation with the probability of illegal information disclosure.

(2) Board Characteristics and Illegal Information Disclosure

The study of $\mathrm{Yu}$ Xiao-qiang and Liu Shan-cun(2012)showed that although the proportion of independent directors shows negative correlation with the probability of illegal information disclosure, it is not significant; Yang Qing-xiang etc(2009)held the opinion that the board stability negatively related to listed company's financial fraud. The study of $\mathrm{Li}$ Zhong(2012)found that the in-year change of chairman or general manager of listed companies had a significant adverse impact on the quality of information disclosure; the study of Beasley(1996) and MCMullen(1996)showed that the establishment of the Audit Committee in the Board of Directors can significantly reduced the incidence of financial fraud of listed companies. In summary, we propose the following hypothesis:

H2a: Proportion of independent directors shows negative correlation with the probability of illegal information disclosure.

H2b: Board of stability shows negative correlation with the probability of illegal information disclosure.

H2c: The existence of audit committee shows negative correlation with the probability of illegal information disclosure.

(3) Managers Equity Incentives and Illegal Information Disclosure

According to Healy and Wahlen(1999), because of the existence of strong relation between the interests of managers and stock price, in order to obtain short-term interests on the secondary market, managers holding high proportion of stock equity may disclose false information, thus increasing the likelihood of illegal information disclosure. Therefore, we propose the following hypothesis:

H3: Managers equity incentives shows positive correlation with the probability of illegal information disclosure. 


\section{B. The Influence of Financial Characteristics on Illegal} Information Disclosure

The study of Zhang Cheng-rui and Jian Jing(2008)showed that under the circumstance of controlling other factors, the worse the profitability of listed companies, the higher likelihood of occurrence of illegal information disclosure; Based on the agency cost theory, Li Zhong(2012)concluded that the weaker thecompanies' solvency become, the higher the agency coss spend by creditors to protect their own interests was. To reduce the resulting adverse impact, the company tends to enhance the quality of information disclosure to obtain the trust of creditors. Therefore, we propose the following hypothesis:

H4: Corporate profitability shows negative correlation with the probability of illegal information disclosure.

H5: Company solvency shows negative correlation with the probability of illegal information disclosure.

\section{The Influence of External Environment on Illegal}

\section{Information Disclosure}

There are a few scattered literatures considering external environment. Using the companies occurring illegal information disclosure in 1998-2007 as the study sample, the study of Yu Xiao-qiang and $\mathrm{Li}$ Shan-cun(2012)showed that listed companies in more developed markets had a lower likelihood of occurrence of illegal information disclosure; According to Ferguson etc(2002), compared with the companies only listed on the local exchange, Cross-listed companies in Hong Kong have a higher quality of information disclosure. Fang Hong-xing etc(2009)found that the quality of information disclosure of internal control was significantly negatively correlated with external audit opinion type. Therefore, we propose the following hypothesis:

H6: The level of development of the area where listed company located shows negative correlation with the probability of illegal information disclosure.

H7: The degree of legal protection shows negative correlation with the probability of illegal information disclosure.

H8: Audit opinions show negative correlation with the probability of illegal information disclosure.

\section{STUDY DESIGN}

Since the "Enterprise Accounting Standards" issued by the Ministry of Finance came into effect in 2007, in order to ensure the reliability and comparability of the sample data, this paper will examine the period 2007-2012, and take listed companies with at least one violations among the action of making up profit, falsifying statement of assets, making false statements (or misleading statements), delaying disclosure, having material omissions and falsifying disclosure (or other) acts etc and confirmed by regulators as samples. Then, in order to carry out comparative studies, we select a paired company disclosing information regularly among 2007-2012 for each sample within the same stcok exchange, among the same industry and the closest time to be listed.

The main source of data is the GTA database, supplemented by information on the Shanghai Stock Exchange and the Shenzhen Stock Exchange official website. Definition of non-compliance year is as follows: In the period of 2007-2012, if listed company turns out illegal information disclosure for one time, then marking that year as non-compliance year; If the violation occurs repeatedly, then markings the first time as non-compliance year. From 2007 to 2012, the number of the listed companies occurred illegal information disclosure and confirmed by the Commission, the Shanghai Stock Exchange, the Shenzhen Stock Exchange and the Ministry of Finance and other regulatory authorities is 294, considering the matching of the sample companies and the paired companies and data availability and integrity, we finally determine the sample companies and the paired companies each 196.

Since the dependent variable is binary classification dummy variable, in order to enhance the soundness and effectiveness of the inspection, we use logistic regression models for data analysis.

\section{THE EMPIRICAL ANALYSIS AND TEST}

\section{A. Descriptive Statistics and Single Factor Tests}

To analyze the basic differences of each variable of the study sample and paired samples, this paper carried out descriptive statistics for all independent variables, and calculated their corresponding maximum, minimum, mean and standard deviation in each groups; this paper adopted paired samples t-test to compare and analyze the means' difference of each factor, and adopted two related sample Wilcoxon test method to compare and analyze the mid-values' difference of each factor.

This paper use Excel 2003 and SPSS20.0 to organize and calculate dates.

From the data which showed that both the paired $t$ test and Wilcoxon test wereat 99\% confidence level, and both the two groups of samples demonstrated significant differences in ownership concentration, stability of the Board of Directors and profitability; at the 95\% confidence level, both the two groups of samples demonstrated significant differences in managers' equity incentive, market development level and audit oversight opinion; while in the proportion of independent directors, audit committees, and the degree of legal protection, two groups of samples did not show a significant difference. In addition, in both the paired $t$ test and Wilcoxon test, two groups of samples demonstrated significant differences respectively at $90 \%$ and $99 \%$ confidence level in solvency.

\section{B. Logistic Regression Analysis and Test}

The company's internal governance model only considers the internal governance and external environmental factors, the company's financial model only considers the company's financial position and external environmental factors, while the company's integrated model considers the combined effect of internal governance, financial position and external environmental factors.

The logistic regression analysis and test results show 
that:

The ownership concentration, the board stability, managers equity incentive, profitability and market-oriented variables have significantly affection on illegal information disclosure, and the sign of the estimated coefficients consistent with the hypothesis that the empirical results support the H1, H2 (2 ), H3, H4 and H6; although the sign of the coefficients of proportion of independent directors, audit committees and other variables consistent with the hypothesis, they don't have significantly affection on illegal information disclosure, which means the data results do not support H2 (1), H2 (3),and our independent director system and the internal audit system are not perfect, and can't achieve effective checks and balances for illegal information disclosure; Cross-listing don't show significantly affection on illegal information disclosure, and the sign of the coefficient is inconsistent with the hypothesis (ie, data results do not support H7), that may because the current number of cross-listed companies is relatively small in China, and can't reflect the basic difference between the illegal company and the legal company.

Comparing the regression results of the three models, we can come to the conclusion that managers' equity incentive is more significant in the integrated model, the solvency which isn't significant in the financial position model is more significant in the integrated model (i.e. data results in the integrated model supports H5), while the external audit and supervision which is more significant in the internal governance model isn't significant in the financial position model and the integrated model(i.e. data results in the integrated model don't supports H8). To sum up, the integrated model is more comprehensive and reasonable than the internal governance models and financial situation model concerning the overall effect.

\section{CONCLUSIONS}

In the case of other variables held constant, because listed companies' stock are relatively concentrated, the largest shareholder increases the shareholding ratio may be helpful to restrain the illegal information disclosure of the listed companies; Board of instability (i.e. frequent changes in the president or general manager) could significantly increase the probability of occurrence of illegal information disclosure, while the increase in the proportion of independent directors did not significantly reduce the likelihood of illegal information disclosure; increasing the proportion of managerial ownership, may significantly increase the likelihood of illegal information disclosure; in addition, the establishment of an audit committee didn't have a significant impact on controlling and supervising of illegal information disclosure. Therefore, to reduce the likelihood of illegal information disclosure, and improve the quality of information disclosure, policymakers need to further improve the corporate governance structure; to maintain the controlling shareholder status of ownership concentration of company, to maintain the relative stability of the Board of Directors, and to strengthen the independence of the independent directors, in the case of the stock market immaturity, the intensity of managers equity incentive shouldn't be increased. In addition, the company is required to effectively enhance the level of internal control, including the audit committee.

\section{ACKNOWLEDGMENTS}

This paper was partly supported by the Fundamental Research Funds for the Central Universities, China (27R110650B0).

\section{REFERENCES}

[1] Ball, R., Robin, A. and Wu, J. S., Incentives Versus Standards: Properties of Accounting Income in Four East Asian Countries. J. Accounting and Economics, 2003, 36(1 3): p235-270

[2] Persons O. S. Corporate Governance and Non-Financial Reporting Fraud. J. Business \& Economics Studies. 2006, 12(1): p27-38

[3] Klapper, L. F. and Love, I., Corporate Governance, Investor Protection and Performance in Emerging Markets. J. Corporate Finance, 2004,10(5): p703-728

[4] Williams, R., Using Heterogeneous Choice Models to Compare Logit and Probit Coefficients across Groups. University of Notre Dame working paper, 2008.

[5] Yi Zhihong, Jiang Fuxiu and Qin Yihu. The Market Competition in Products, the Corporate Governance and the Quality of Information Disclosure. Management World. 2010,1: p133-141.(In Chinese)

[6] Yueming Zeng, Tengfei Lu, Wenli Tang. Statistical Model for Personal Characteristics of and Quality of Information Disclosure. International Journal of Applied Mathematics and Statistics, 2013, 49(19),p174-182 